\title{
Claves para trabajar la entonación irónica con alumnos de ELE
}

\author{
INÉS SEMPERE SEMPERE \\ Universitat d'Alacant \\ iss23@alu.ua.es \\ Cristina Turcanu VASILIU \\ Universitat d'Alacant \\ ctv8@alu.ua.es
}

Resumen: El objetivo de este trabajo es hacer una propuesta didáctica que ayude a percibir/ producir la entonación irónica a los estudiantes de español como lengua extranjera (ELE). Este trabajo se centrará, en los aspectos fónicos, y especialmente en los entonativos (Lahoz, 2012; Padilla García, 2015), pero tendremos en cuenta también otros ingredientes del fenómeno, como el componente pragmático y el componente cultural. Tomando como punto de partida las indicaciones del MCER (2002) y del Plan Curricular del Instituto Cervantes (2007), pensamos que la ironía es un fenómeno comunicativo que, aun siendo compartido por muchas culturas, puede resultar difícil de manejar por los aprendientes de español. Teniendo en cuenta lo anterior, nuestra propuesta didáctica presentará algunas claves de reconocimiento de la ironía con el propósito de mostrar a los alumnos las particularidades de la entonación irónica, relacionándola, además, con las unidades fraseológicas y con otros indicadores lingüísticos (GRIALE, 2011).

Palabras clave: entonación, ironía, método verbo-tonal, percepción/producción mecánica y consciente, ELE.

\section{Key strategies to work ironic intonation with SSL students}

Abstract: The objective of this paper is to make a didactic proposal in order to help students of Spanish as a foreign language to perceive/produce the ironical intonation. Our purpose is to center the work in the phonic features, especially the ones related to the intonation (Lahoz, 2012; Padilla García, 2015). Besides, we also considered other aspects of this linguistic phenomenon as its pragmatic and cultural components. Following the CEFR and the Cervantes Institute Curriculum Plan, we understand irony as a concept that - even though present in many cultures - can be a notion difficult to manage by foreign learners of Spanish, due to their lack of some historical and encyclopaedical references. Our didactic proposal is based on the presentation of some phono-cognitive strategies of mechanical and conscious perception and production of the ironical intonation, to show the particularities of this concept, both in phrasemes and other linguistic indicators (GRIALE, 2011).

Key words: intonation, irony, verbo-tonal method, pronunciation, SSL.

\section{Introducción}

\subsection{Ironía}

El concepto clave de nuestra unidad didáctica es la ironía $\mathrm{y}$, más concretamente, la entonación que la define y la acompaña. La entonación es un componente más de este 
fenómeno del lenguaje, por lo tanto, nuestra unidad abordará, además, la definición del concepto ironía en general. En este sentido, haremos un repaso introductorio de esta noción para facilitar la activación de los conocimientos previos de los estudiantes y favorecer la adquisición de la nueva información al respecto, a partir de un aprendizaje significativo ${ }^{1}$.

\subsection{Ficha técnica}

\begin{tabular}{|c|c|}
\hline \multicolumn{2}{|c|}{ RECONOCIMIENTO DE LA ENTONACIÓN EN LA IRONÍA } \\
\hline NIVEL & $\mathrm{B} 2, \mathrm{C} 1, \mathrm{C} 2$ \\
\hline OBJETIVOS & $\begin{array}{l}\text { - Activar los conocimientos previos sobre la ironía. } \\
\text { - Desarrollar en el alumno las claves de reconocimiento de la } \\
\text { ironía, tanto a través de indicadores lingüísticos, como a través de } \\
\text { los fónicos. } \\
\text { - Practicar la entonación irónica correcta, y ser capaz de distinguir } \\
\text { la no irónica. } \\
\text { - Aprender los contextos y ámbitos propicios para el uso adecuado } \\
\text { de la ironía. }\end{array}$ \\
\hline DESTREZAS & $\mathrm{CO}, \mathrm{EO}, \mathrm{IO}, \mathrm{EE}$ \\
\hline CONTENIDOS & $\begin{array}{l}\text { - Entonación irónica y no irónica } \\
\text { - Unidad fraseológica: ;Menos mal! } \\
\text { - Estructura irónica con adverbio de cantidad muy: iSí, es muy lista } \\
\text { ella! }\end{array}$ \\
\hline DESTINATARIOS & Jóvenes y adultos \\
\hline DINÁMICA & Individual, grupo \\
\hline DURACIÓN & $2-3$ sesiones de 50 minutos \\
\hline MATERIALES & Pizarra, proyector, ordenador y altavoces \\
\hline $\begin{array}{l}\text { ORIENTACIONES PARA } \\
\text { EL PROFESOR }\end{array}$ & $\begin{array}{l}\text { Los ejercicios están elaborados de manera sucesiva, aunque se pueden } \\
\text { hacer modificaciones según considere el profesor. }\end{array}$ \\
\hline
\end{tabular}

Como hemos explicado anteriormente, nuestra unidad va a apuntar algunas claves para ayudar a percibir y producir la entonación irónica del español. El nivel al que va dirigida la unidad es principalmente un intermedio-alto, es decir, desde un B2 en adelante. No obstante, los materiales se podrán adaptar según considere el profesor adecuándolos al nivel de sus estudiantes. Con respecto a las destrezas, la comprensión, expresión e interacción oral son las predominantes a lo largo de esta.

\footnotetext{
${ }^{1}$ Para información más detallada sobre el tema principal, véase sección 2.1.1.
} 
Tendremos en cuenta, por otra parte, algunas recomendaciones del método verbo-tonal (MVT) del profesor y logopeda Guberina (1961), (citado por Padilla García, 2015: 7576), por ejemplo, el uso de la lengua oral sin combinarla con la lengua escrita, al menos en las fases iniciales del aprendizaje; o la recomendación de no utilizar la lengua materna del estudiante como lengua de instrucción en el aula.

Consideraremos dos ejemplos concretos dentro de la sesión: la unidad fraseológica ¡Menos mal!; y la estructura irónica con adverbio de cantidad muy: iSí, es muy lista ella! Estos, son parte de los llamados indicadores lingüísticos de la ironía ${ }^{2}$.

Los destinatarios principales son jóvenes y adultos. En lo que concierne a la dinámica de las actividades puede ser tanto individual como grupal: toda la clase o grupos de 3-4 personas.

A propósito de la temporalización, a pesar de que aquí expongamos una sesión de cincuenta minutos, puede desarrollarse también a través de varias sesiones; el profesor será el encargado de seleccionar los ejemplos y su organización en el aula. Es aconsejable que los ejemplos compartan características similares con el fin de que los estudiantes los puedan asimilar y relacionar más fácilmente.

Los materiales necesarios para llevar a cabo esta unidad son, principalmente: pizarra, proyector y ordenador con altavoces. Para la realización de otras actividades más concretas precisaríamos de dos cajitas o bolsas (Act. 4. "Ironiza como puedas"), y, de forma opcional, para el trabajo en casa: corcho o cartulina, hilos y chinchetas ${ }^{3}$.

Aunque los ejercicios han sido diseñados de manera consecutiva, el profesor puede realizar las modificaciones que crea pertinentes.

\subsection{Secuencia de actividades}

El orden y elección de contenidos se ha hecho siguiendo las pautas fono-cognitivas de percepción y producción mecánica/consciente de las entonaciones irónicas (Padilla García, 2015). Como ya mencionamos en la ficha técnica de la sesión, nuestro objetivo final es conseguir la articulación más libre y natural de este fenómeno lingüístico y pragmático, mediante el reconocimiento de las funciones y propiedades específicas de la ironía.

A diferencia de las propuestas fonoarticulatorias -las más usadas tradicionalmente para impartir la fonética de una LE/L2-, nosotros reivindicamos el componente suprasegmental. Es decir, proponemos comenzar, como señala el método verbo-tonal, por los elementos suprasegmentales (también llamados prosodemas), como el ritmo, acento y la entonación. Creemos -en este sentido- que la pronunciación no puede centrarse exclusivamente en los sonidos aislados, sino que estos últimos deben presentarse teniendo en cuenta sus propiedades combinatorias más comunes o más adecuadas a los objetivos fijados en cada momento del proceso de aprendizaje. Es por ello por lo que el método verbo-tonal aconseja impartir primeramente los suprasegmentos, y posteriormente los segmentos lingüísticos (fonemas) y sus combinaciones.

Teniendo en cuenta los patrones previamente mencionados adoptamos una perspectiva didáctica en la que predomina el input oral y auténtico, y que sigue un esquema

\footnotetext{
${ }^{2}$ Véase la tabla de indicadores de la ironía en el Anexo 1.

${ }^{3}$ Véase un ejemplo en el Anexo 4.
} 
deductivo centrado desde lo más general a lo más particular. Mantendremos, además, una progresión de la dificultad que, favorece primero una percepción consciente (de la entonación irónica), y, posteriormente, una producción consciente, que se convertirá tras la práctica de las actividades-en inconsciente.

El proceso de aprendizaje se culmina con la utilización de elementos lúdicos que propician un ambiente de clase distendido y cómodo, auspiciando la asimilación y automatización de los rasgos fonéticos (de la ironía, en este caso) de una manera más sencilla ${ }^{4}$.

\section{Unidad didáctica}

\subsection{Conceptos básicos de la unidad didáctica}

\subsubsection{Ironía}

\subsubsection{Definición y características distintivas}

Tradicionalmente, un enunciado se considera irónico cuando su verdadero significado contradice la literalidad, es decir, cuando el oyente debe interpretar lo contrario de lo que escucha. No obstante, hoy en día, existen numerosos ejemplos que invalidan dicha definición. Tal y como señalan algunos autores (Ruiz Gurillo y Padilla García, 2009), el denominador común de los enunciados irónicos es la deducción de una parte del contenido para elaborar el significado completo y no la contradicción per se -en otras palabras- una fracción del enunciado contiene los matices pragmáticos específicos que afectarían al sentido global de toda la frase, y no necesariamente mediante la contradicción u oposición, como habitualmente se señala.

Asimismo, debido a la ironía se manifiesta a través de indicadores de diversa índole, es necesario igualmente relacionarla con la cultura en la que se produce (véase sección 2.1.1.2 indicadores). Por todo ello, los estudiantes necesitan no solo un alto grado de dominio de la lengua, sino también de su historia, cultura, etc., que acompañan a los enunciados irónicos. De ahí que sea recomendable presentar y definir este concepto a partir de los niveles intermedios-altos de dominio de la L2, para así favorecer una comprensión más profunda y nítida del fenómeno.

En el procesamiento auditivo de la ironía, el aprendiente activa y emplea diversas competencias para discernir el significado de los enunciados, a saber: varias subcompetencias comunicativas, como la gramatical, discursiva, sociolingüística y estratégica (Canale y Swain, 1980, 1996), a la que debe sumarse la competencia intercultural (Byram, 1995; Jaeger, 1995; y Oliveras Vilaseca, 2004), y algunos tipos de conocimientos como el fonológico, sintáctico, semántico y pragmático (Flowerdew y Miller, 2005). Tal y como afirma Martín Leralta (2009), existen diversas tareas a desempeñar por parte del aprendiente para conseguir procesar con éxito la información escuchada:

a. Recepción de la onda sonora

b. Identificación de sonidos pertinentes

\footnotetext{
${ }^{4}$ Véase el Anexo 5 para la visualización de la propuesta, siguiendo el enfoque fono-cognitivo planteado por parte del profesor Padilla (2015: 77).
} 
c. Selección de información relevante

d. Análisis y elaboración del significado

e. Retención de información

f. Recuperación de la misma ${ }^{5}$

Por último, cabe destacar el prisma afectivo y social, a través de la cual los oyentes filtran de manera inconsciente la información de entrada. Se incluyen en dicho prisma las motivaciones, actitudes, necesidades y los estados de ánimo de cada individuo, lo que denota un añadido más de dificultad para su detección por parte de los aprendientes ${ }^{6}$.

\subsubsection{Indicadores}

La ironía es un concepto complejo que requiere de la activación de numerosas estrategias de reconocimiento y producción en los aprendientes. Por suerte para ellos, este fenómeno pragmático se apoya en una amplia serie de indicadores, tal y como confirma GRIALE? ${ }^{7}$ En ella, los encontramos clasificados como lingüísticos y no lingüísticos, de textos tanto orales como escritos ${ }^{8}$ :

\section{a) Indicadores no lingüístico}

- Indicadores kinésicos: gestos, maneras y posturas.

- Indicadores paralingüísticos: entre risas, risas, silencio, bostezo, carraspeo, estornudo, grito, jadeo, llanto, soplo y acotadores literarios (p.e. con retintín).

- Indicadores acústico-melódicos: entonación irónica, foco enfático, pausa, silabeo, vacilación, velocidad de emisión y voz de falsete.

\section{b) Indicadores lingüísticos}

- Puntuación: comillas, signos de exclamación, signos de interrogación, puntos suspensivos, paréntesis y guiones, entre otros.

- Cambios tipográficos: cursiva, negrita y versales.

- Variación lingüística: cambios de código (p.e. denominaciones técnicas inventadas para las profesiones en registros informales), variación diacrónica, diatópica, diastrática y diafásica.

- Palabras de alerta: encomiásticos, términos valorativos, evidenciales, marcadores del discurso, eufemismos, polisemia, homonimia, antonimia y pseudo-abarcadores.

- Unidades fraseológicas: uso canónico, uso desautomatizado.

\footnotetext{
${ }^{5}$ (Martín Leralta, 2009: 52)

${ }^{6}$ Ibidem

${ }^{7}$ El Grupo GRIALE (Grupo de Investigación sobre la ironía y el humor en español), fundado en 2002, pertenece al Departamento de Filología Española, Lingüística General y Teoría de la Literatura de la Universidad de Alicante.

${ }^{8}$ (Ruíz Gurillo, 2008: 6)
} 
- Formación de palabras: sufijación, prefijación, composición y otros mecanismos de creación léxica.

- Figuras retóricas: repetición, simplificación, yuxtaposición, lítote, hipérbole, oxímoron, metáfora, paradoja, antítesis y otros juegos de palabras.

- Discurso directo

- Orden anómalo de palabras

Todos los indicadores mencionados deben ser presentados al alumnado con mayor o menor profundidad en función de las necesidades de este, ya que, en conjunto, todos ellos pueden conllevar significado irónico al discurso, y, por lo tanto, los aprendientes deben estar familiarizados con todas las formas de expresar ironía, tanto para ser capaces de reconocerla en primer lugar, y poder producirla posteriormente.

\subsubsection{3. Ámbitos recomendados de uso}

Dentro de un aula multicultural y heterogénea es posible encontrar aprendientes en cuyos senos culturales de origen la ironía no tenga suficiente aceptación social o incluso no tenga cabida. Es importante que el docente sea consciente de las características y necesidades de sus alumnos para poder estar preparado y proporcionar explicaciones acerca de la ironía desde distintas perspectivas, con tal de cubrir las necesidades de los aprendientes que no estén familiarizados con ella.

Como mencionamos anteriormente, este fenómeno pragmático requiere de la activación de la competencia intercultural entre la realidad cultural de origen de los estudiantes y la cultura meta. A pesar de que la sociedad de origen pueda tener una idea diferente de la ironía, los alumnos de español deberán ser capaces de entenderla, identificarla en otros hablantes, e incluso producirla de igual manera. Será, por tanto, importante que el profesor disponga de numerosas estrategias de enseñanza y ejemplificación del tema para poder evitar posibles choques culturales antes de que estos ocurran. El docente tendrá que remarcar la importancia de la adecuación y coherencia del uso de la ironía en función del nivel de formalidad del contexto lingüístico, así como con el nivel de familiaridad de los interlocutores.

En este sentido, el marco más adecuado para el uso de la ironía es el que se halla en un ambiente de confianza y distensión, y consecuentemente, en un entorno más bien informal, aun cuando sea común encontrar trazas irónicas en la televisión y en la prensa.

\subsubsection{La entonación y sus funciones}

La entonación es el resultado de la integración de la melodía y el acento.

La melodía y el acento forman parte del conjunto de elementos suprasegmentales:

La melodía:

a. Articulatoriamente: representa las variaciones en la frecuencia de vibración de las cuerdas vocales a lo largo de un enunciado.

b. Acústicamente: es la evolución de la frecuencia fundamental en el tiempo (curva melódica). 
c. Perceptivamente: presenta los cambios en la altura tonal (agudo/grave) en el enunciado.

El acento:

a. Articulatoriamente: representa el incremento de la frecuencia de vibración de las cuerdas vocales y de la fuerza y el tiempo de salida del aire.

b. Acústicamente: es el aumento de frecuencia fundamental de intensidad o de duración de una sílaba.

c. Perceptivamente: refiere la prominencia en la altura tonal (agudo), en la intensidad (fuerte) o en la duración (largo) de una sílaba9 .

Según Llisterri (2004: 1-2), clasificaríamos las funciones de la entonación de la siguiente manera:

a. Función gramatical distintiva

b. Información nueva en el discurso

c. Función enfática

d. Función expresiva

e. La entonación en las lenguas

En el caso de la ironía destacan, sobre todo, la función enfática y la expresiva:

a. Función enfática: la entonación sirve para destacar o enfatizar elementos del discurso.

b. Función expresiva: la entonación introduce matices en el significado del enunciado. ${ }^{10}$

\subsubsection{Método Verbo-Tonal}

En los años cincuenta, surgen los dos métodos principales para la enseñanza de la fonética: el método verbo-tonal y el método fonoarticulatorio; nosotros nos centraremos en el primero, aunque sea el segundo el más conocido y extendido. El método verbotonal surge de la mano del humanista y terapeuta croata Petar Guberina (1961). En un principio, el propósito de su creación surge a raíz de la necesidad de ayudar a los niños con problemas de audición a pronunciar correctamente. De este origen deriva una de las premisas verbo-tonales más relevantes: si no somos capaces de percibir sonidos, no podremos producirlos. Es por esto por lo que se le da especial importancia a la percepción, que, en situaciones favorables, llevaría de una manera natural a la producción. El proceso de aprendizaje comienza, por lo tanto, por la percepción y, luego, el aprendiente iniciará una segunda fase del aprendizaje con la producción.

Al contrario que el método fono-articulatorio, el método verbo-tonal opta por trabajar primero con los suprasegmentos: entonación, ritmo y acento; desde lo más grande a lo más pequeño.

\footnotetext{
${ }^{9}$ Llisterri, 2004: 1-2)

${ }^{10}$ Ibidem (1-8)
} 
Otro aspecto a destacar en dicho método es la exclusividad del uso de la lengua meta. Se inicia el aprendizaje desde la oralidad, evitando el apoyo de material escrito, y utilizando únicamente la lengua meta.

Dejando a un lado los sonidos, y haciendo referencia a la kinesia, el método verbo-tonal señala que la microcepción se ve influida por la macrocepción. La tensión que uno tenga en el cuerpo afectará a la tensión con la que produzca sonidos concretos. Los gestos para este método son elementos fundamentales para interpretar sonidos.

\subsubsection{Praat}

Praat (http://www.fon.hum.uva.nl/praat/) es un programa informático de acceso libre creado por Paul Boersma y David Weenink en la Universidad de Ámsterdam en 1992, diseñado especialmente para estudiar e investigar particularidades fonéticas. Entre muchas otras opciones, permite hacer análisis acústicos, procesamientos estadísticos de datos, edición y manipulación de audio y un largo etcétera. En nuestro caso, lo hemos usado para el análisis de la entonación irónica. Como sus posibilidades son muchas, aconsejamos a los interesados consultar algunos de los tutoriales más importantes sobre el uso del programa, así como la web del profesor J. Llisterri (http://liceu.uab.es/ joaquim/phonetics/fon_Praat/Praat.html).

\subsubsection{Indicaciones para la realización de las actividades}

\subsubsection{Actividad de introducción}

Para dar comienzo a la sesión de una manera distendida y cómoda, comentaremos con nuestros alumnos el concepto de ironía. Esto nos proporciona un triple beneficio: por un lado, rompemos el hielo y favorecemos la comunicación, también averiguamos qué conocimientos tienen acerca de la ironía nuestros alumnos y si la suelen usar de forma cotidiana, y, finalmente, los incluimos activamente en la clase, haciendo que compartan sus particularidades personales y culturales.

Cabe destacar, además, que es una excelente oportunidad de potenciar la competencia intercultural de nuestros alumnos, si se da el caso de que alguno de ellos desconozca o no haya usado nunca un enunciado irónico.

Se puede guiar este pequeño debate inicial mediante las siguientes preguntas:

- ¿Cómo concibe la ironía tu cultura?

- ¿Sabrías detectar rasgos de la ironía en tu lengua materna?

- ¿Te consideras irónico?

- ¿Pensáis que los españoles somos irónicos?

Las preguntas han sido ideadas para conseguir un proceso de reflexión y conciencia lingüística. Se sigue un patrón deductivo, de lo general a lo particular, con respecto al enfoque de las preguntas: se comienza indagando acerca de la ironía en la cultura de origen, primero de manera más general y posteriormente a través de sus rasgos distintivos; seguidamente, el enfoque se desplaza hacia la figura del alumno de forma personal, para incluirlo y hacerle pensar, y finalmente se encamina el debate hacia la ironía en la cultura meta - la española.

\subsubsection{2. ¡Escucha y repite!}




\subsection{Presta atención a las diferentes entonaciones y ¡repite!}

Esta actividad nos sirve como presentación de las entonaciones a estudiar, es decir, en este momento, da comienzo el proceso de aprendizaje de la entonación irónica.

Los alumnos son expuestos a las grabaciones de voz que contienen las pautas fonológicas de los ejemplos seleccionados, a través de la primera fase del aprendizaje mediante el método verbo-tonal: la de percepción mecánica. Éstos se familiarizarán, tanto con las entonaciones neutras de los enunciados, como de las irónicas, para poder discernir entre ellos en futuras situaciones lingüísticas reales.

Para una rápida relación de conceptos, asociamos dos emoticonos para representar la entonación irónica $\because$ y no irónica $(A)$ respectivamente. Consideramos que puede ser una manera clara de simbolizar la función irónica del lenguaje, que, además, aporta cierta información kinésica real que normalmente la acompaña.

Puesto que el concepto de la ironía puede resultar complejo, incluso para aprendientes avanzados, se invita al docente a repetir las grabaciones con las entonaciones las veces que sean necesarias (dentro de las posibilidades de tiempo de clase), ya que estas representan la base cognitiva de imitación y ejemplo sobre la que se depositarán los siguientes niveles de aprendizaje de la ironía en el español.

Tras escuchar los audios ${ }^{11}$, los alumnos habrán de repetir los ejemplos intentando imitar la entonación que acaban de escuchar.

\subsection{Balé con las ondas}

Como parte de las directrices del método verbo-tonal ${ }^{12}$, y, para conseguir un aprendizaje más efectivo de la perspectiva fonológica de la ironía, queremos crear la percepción consciente de las distintas curvas melódicas presentes en nuestros ejemplos empleados. Para ello, nos ayudamos de la F0 (frecuencia fundamental) resultante de las grabaciones, y, con la ayuda del programa PRAAT y Microsoft Excel, creamos gráficas de las curvas melódicas de los enunciados irónicos presentados, como las que podemos observar en la imagen 1.

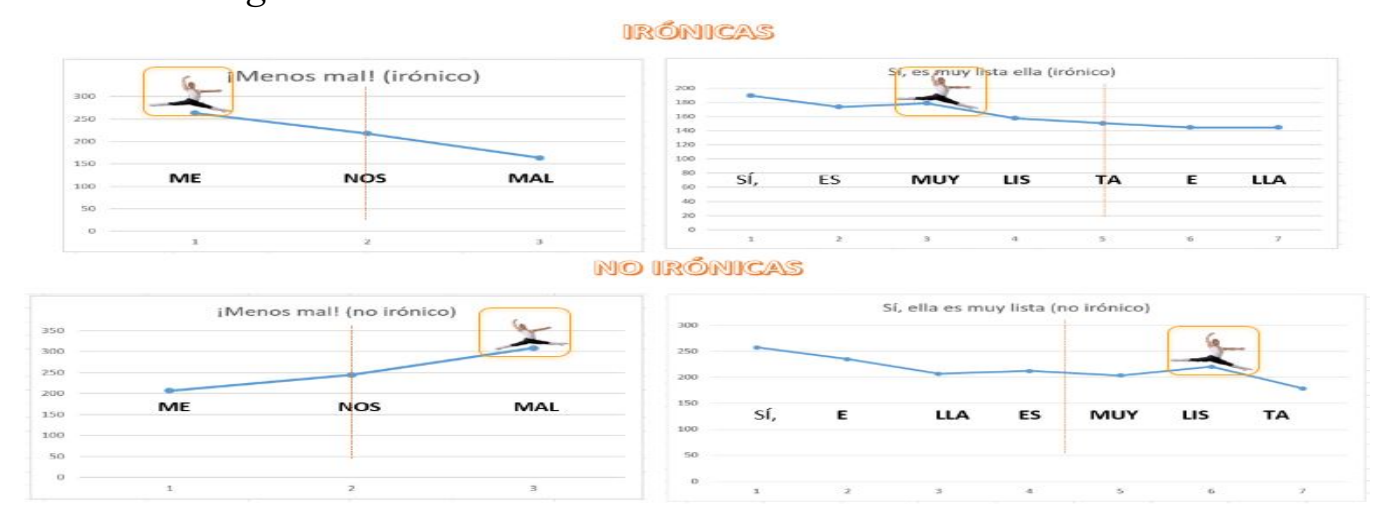

Imagen 1. Gráfica de las curvas melódicas de los enunciados irónicos presentados.

En las gráficas podemos observar una serie de parámetros (segmentos) que cambian en función de las características particulares de las F0 de los ejemplos, que denotan los

\footnotetext{
${ }^{11}$ Véanse los espectrogramas correspondientes en el Anexo 3

${ }^{12}$ Método Verbo-Tonal. Véase sección 2.1.3. para más detalle del método.
} 
altibajos relativos al foco acentual. Tal y como exponen Padilla y Ruíz (2009), la focalización es un fenómeno habitual en los estudios fonológicos y representa la manera más fácil de realzar los parámetros de interés a enfatizar, en este caso, el realce acentual o entonativo, también llamado foco acentual.

Para hacer más asequible la asociación entre estos conceptos, empleamos la figura de un bailarín de balé, que guarda semejanza con las formas de la variación fonológica del foco acentual de nuestros ejemplos.

Además, como también afirma Padilla, de manera general, los enunciados irónicos son propensos a presentar fuertes ascensos y descensos, dentro de un contorno entonativo circunflejo, que se recoge de esta manera por representar valores emotivos como la alegría, ira, tristeza, y también ironía.

En el caso de nuestros dos ejemplos, hemos constatado que, el rasgo distintivo sobre el que queremos llamar la atención de los alumnos es el foco acentual, que se encuentra en la segunda mitad del enunciado, tal y como se puede apreciar en la imagen 1. En el caso de las entonaciones neutras, contrariamente, el foco acentual se sitúa en la segunda mitad del enunciado.

Haríamos explícitas las indicaciones de la posición del foco acentual, con el objetivo de que nuestros alumnos la memoricen de la manera más rápida y sencilla posible. Aun así, somos conscientes de la dificultad del éxito absoluto de esta tarea, a pesar de haber usado imágenes con las que se pueden relacionar visualmente. Por ello, introducimos otra estrategia de aprendizaje -el silabeo- con la ayuda del cual se pueden enfatizar los altibajos de las entonaciones mencionadas previamente.

Las grabaciones se reproducirían primero a una velocidad normal y sin silabeo, y, después, con la ayuda del profesor, los alumnos repetirían las distinciones fonológicas sílaba por sílaba, para, finalmente, intentarlo hacer, pronunciando la frase de manera seguida y, acercándose lo máximo posible al ejemplo grabado.

\subsection{Ahora, escucha estos ejemplos y escoge la entonación adecuada dependiendo del contexto, luego repítela}

En esta segunda parte de la actividad dos, aumentamos ligeramente el nivel de dificultad: los alumnos deben averiguar/intuir qué entonación (irónica o no) será la adecuada en una serie de viñetas que les enseñamos. Habrán de hacerlo en base a los contextos y diálogos.

Cada viñeta viene acompañada de una imagen y un contexto. Los alumnos ven las imágenes mientras escuchan las grabaciones para poder conseguir un acercamiento lo más claro y auténtico posible a situaciones reales de uso de la ironía.

Primero, se escucha sólo un fragmento del audio, es decir, evitando reproducir el enunciado irónico. De esta manera el profesor puede pedirles que decidan cuál de las dos entonaciones es más adecuada según la situación ejemplificada.

Una vez se llegue a una respuesta común, se reanudará el audio y se desvelará la entonación adecuada, comprobándose de este modo si la respuesta proporcionada por la mayoría es correcta o no. 
En el caso negativo, el docente resolverá las dudas pertinentes y reforzará una vez más las características particulares de cada entonación reproduciendo y repitiendo las grabaciones de la actividad 2.1.

\subsubsection{Encuentra la ironía}

\subsection{Identifica la ironía en los siguientes fragmentos y di qué te ha ayudado a hacerlo}

Siguiendo la progresión de la unidad didáctica, en este punto, los alumnos tendrán que identificar ellos mismos dónde se encuentra la ironía (si la hay). Como, además, se pide que expliquen qué factores les han ayudado a reconocerla, el alumno tendrá que analizar bien los contextos.

Para darles algunas pautas más generales acerca de las características de la ironía y su detección, una vez comiencen a contestar, añadiremos en la pizarra los conceptos mediante los cuales comúnmente se componen las ironías:
a. La exageración (audio 1);
b. La negación del enunciado (audio 2);
c. El significado contrario de lo que se dice (audio 3).

Consideramos estas tres características como las más habituales y fácilmente detectables. Una vez el alumnado las comprenda y asimile, será más fácil para ellos intentar detectar la ironía en otros ejemplos distintos a los vistos en clase.

\subsubsection{4. ¡Ironiza como puedas!}

Esta es la última y más "libre" de las actividades de nuestra unidad didáctica. Mediante las tres secciones que la componen, pretenderemos conseguir por parte de nuestros aprendientes una fácil producción consciente, con el objetivo de convertirla en inconsciente en la mayor brevedad posible.

Para realizar el primer apartado, se depositan dos cajas en una mesa enfrente de toda la clase. En una de ellas se contendrán los ejemplos de unidades fraseológicas estudiados en clase (imenos mal! y imuy listo/a!) así como otras formas (iqué bonito! y otros ejemplos de construcciones con el adverbio de cantidad muy: ;muy bueno/a!; ;muy inteligente!; ;muy responsable! ...etc.). Por un lado, repasamos los ejemplos vistos durante la sesión, y por otro, introducimos más variedad y flexibilidad de elección reforzando los patrones fonoarticulatorios aprendidos, puesto que los nuevos ejemplos se han seleccionado para coincidir en las pautas fonológicas con los dos ejemplos iniciales.

En la segunda caja se encuentran las distinciones entre entonación irónica o neutra.

2.1.5.4.1. Por grupos (3-4 pers.), coged un papel de cada caja: de la primera sacaréis una frase; de la segunda, su entonación -irónica o no irónica. Deberéis ser capaces de pronunciar vuestra frase adecuadamente

La primera parte de esta actividad consiste en la elección al azar de un enunciado. Tras la selección, cada miembro del grupo tendrá pronunciar adecuadamente el enunciado escogido.

2.1.5.4.2. En casa, a partir de la frase y entonación que habéis sacado, deberéis crear un contexto adecuado, que se representará en forma de diálogo en la siguiente sesión 
Para poder acabar de fijar los conocimientos referentes a los elementos fonológicos y lingüísticos estudiados, proponemos a los alumnos escribir el/los enunciado/s que hayan obtenido de las cajas, y por parejas o grupos, crear -ya en casa con más tiempo y menos presión- un contexto adecuado para él/ellos.

En la siguiente sesión, saldrían los grupos a representar sus pequeños diálogos o situaciones delante de sus compañeros.

2.1.5.4.3. Además, habréis de crear en clase, en la próxima sesión, las curvas entonativas (de forma aproximada) de vuestra frase, teniendo en cuenta la posición del foco acentual. Tomaremos como ejemplo el modelo que presentaremos en clase ${ }^{13}$

Para acabar de retener las características y posiciones de los tonemas (irónicos y neutros), les pediremos a los alumnos que creen la curva entonativa de las frases elegidas, de forma aproximada, en el tablero o corcho que pondremos en clase. De este modo, acabarán reforzando la memorización consciente de las particularidades ascendientes y descendientes de las entonaciones en los enunciados irónicos.

Les recordaremos que habrán de tener en cuenta la entonación y posición del foco acentual, y que lo tendrán que hacer con la ayuda del programa informático PRAAT, ya descrito y explicado con más detalle en la sección 2.1.4. ${ }^{14}$

\section{Reflexión post exposición}

\subsection{Conclusiones}

La realización de este trabajo, así como de la unidad didáctica, ha resultado en una experiencia enriquecedora debido a que en pocas ocasiones anteriores habíamos tenido la oportunidad de ahondar tanto en la fonética y la fonología española enfocada hacia la enseñanza de ELE.

El tema tratado en el trabajo también fue muy motivador y apasionante, así como el uso del método verbo-tonal en nuestra unidad didáctica para trabajar la competencia fonopragmática. En este punto, coincidimos con González Berrio y Martín Leralta (2015) al proponer que los contenidos fonopragmáticos se incluyan y amplíen, tanto en el MCER (2002), como en el PCIC (2007), ya en los niveles iniciales. De esta forma, el material trabajado podría adaptarse a otros niveles, beneficiando a muchos más alumnos.

Finalmente, tras esta investigación, hemos vuelto a comprobar la importancia de un estudio más profundo y analítico de los elementos suprasegmentales de la lengua meta, dado que un buen dominio de éstos formaría una gran parte de la competencia en la L2, que todavía no recibe la atención que se merece en el modelo tradicional fono articulatorio.

\subsection{Limitaciones y futuras investigaciones}

A la hora de realizar este trabajo y seleccionar los ejemplos a tratar, nos encontramos con varios factores que, en un principio, retrasaron nuestra tarea; nos referimos con esto, a la forma mediante la cual distinguir una entonación irónica de la no irónica. Claro está que, nuestros alumnos ya estarán familiarizados con el concepto de la ironía, en mayor o

\footnotetext{
13 Véase Anexo 4.

${ }^{14}$ Se añade la ficha del alumno - véase Anexo 2.
} 
menor medida; las complicaciones llegaron en el momento de representarlo de forma visual. A pesar de la dificultad de encontrar algún rasgo visual en común para poder identificar una entonación concreta, finalmente, encontramos la forma en que lo pudimos "escenificar" - la figura del bailarín marcando el foco acentual en la primera mitad (entonación irónica) o en la segunda (entonación no irónica)-.

Debido a que en esta propuesta no especificamos un contexto lingüístico determinado, en cuanto a la edad de los alumnos, sus características psico-sociales o la naturaleza de sus lenguas maternas, nos ha resultado imposible diseñar actividades de contraste lingüístico, ubicado en la fase 3 del aprendizaje fono-cognitivo del enfoque verbo-tonal. Para ello necesitaríamos, como mínimo, conocer con exactitud las L1 de nuestros alumnos. Es por ello por lo que este apartado puede ser una excelente idea inicial para investigaciones ulteriores.

Partiendo desde la idea anterior, podríamos considerar, además, dependiendo de la lengua materna que tengan los estudiantes, averiguar y presentar, los errores más comunes que se puedan producir. De esta forma, facilitaríamos a los futuros profesores su tarea de corregir, o incluso prevenir, los posibles errores de los estudiantes.

Tal y como postula este método, la pronunciación no es independiente de la kinesia, el sonido es considerado un tipo de gesto (Padilla, 2015: 75-76). Es por esto por lo que nos planteamos, como futura investigación, trabajar combinando la kinesia (gestos, miradas, risas o sonrisas), junto con los otros indicadores de la ironía como los lingüísticos y los fónicos -que ya tratamos en este trabajo-. Bien es cierto que, en esta unidad manejamos ciertos indicadores lingüísticos (“imenos mal!” y “imuy lista!”) y fónicos (entonación); pero, la idea que presentamos en este apartado sería una combinación de todos estos indicadores, con tal de conseguir un entendimiento global del concepto de la ironía. Otro punto en el que esta propuesta combinatoria sería fundamental es el hecho de que la kinesia es vital a la hora de pronunciar sonidos, es decir, una orden acompaña un movimiento y un contorno entonativo.

\section{Bibliografía}

BYRAM, M. (1995). «Acquiring intercultural competence. A review of learning theories». En L. Sercu. (Ed.), Intercultural Competence, Vol. I, (pp. 53-67). Denmark: Aalborg University Press.

CANale, M. y Swain, M. (1980). «Theoretical Bases of Communicative Approach to Second Language Teaching and Testing, in Applied Linguistics». En S. Posteguillo y otros (eds.) Methodologies and New Technologies in Languages for Specific Purposes (pp. 79-116). Castellón de la Plana: Publicacions de la Universitat Jaume I.

CANALE, M. y SWAin, M. (1996). «Fundamentos teóricos de los enfoques comunicativos», Signos, 17, 54-62.

GonZÁlez Berrio, S., Y MARTín LeRALTA, S. (2015). La comprensión auditiva de la entonación irónica en alumnos de ELE brasileños con un nivel C1. Recuperado el 3 de enero, de 2019, de: https://revistas.uca.es/index.php/pragma/article/view/2177/2063 DOI: http://dx.doi.org/10.25267/Pragmalinguistica.2015.i23.0

GRIALE (2011). ¿Estás de broma? 20 actividades para practicar la ironía en clase de ELE. Madrid: Edinumen. 
GuBERINA, P. (1961). «La méthode audio-visualle structuro-globale et ses implications Dans l'enseignement de la phonétique», Studia Romanica et Anglica Zagrabiensia, 11, $12-40$.

JAEGER, K. (1995). «Teaching culture-state of art». En A. Jensen y otros (eds.) Intercultural Competence, 2, 19-28.

Lahoz, J. M., LuQue, S., Mellado, A., Y Rico, J. (2012). "Aproximación a la enseñanza de la pronunciación en el aula de español». J. Gil (ed.), Claves para la enseñanza del español (pp. 93-103). Madrid: Edinumen.

LLISTERRI, J. (2004). Las funciones de la entonación. Recuperado el 29 de diciembre, de 2018 ,

de:

http://liceu.uab.es/ joaquim/phonetics/MMI_04/MasterMediacionUAB_04.pdf

Consejo de Europa (2002). Marco Común Europeo de Referencia para las Lenguas: Aprendizaje, Enseñanza y Evaluación. Madrid: Instituto Cervantes- Biblioteca nueva.

MARTÍN LERALTA, S. (2009). Competencia estratégica para la comprensión auditiva en español como lengua extranjera. Madrid: Ministerio de educación, cultura y deporte.

OLIVERAS, À. (2004). Hacia la competencia intercultural en el aprendizaje de una lengua extranjera. Estudio del choque cultural y los malentendidos. Barcelona: Edinumen.

Padilla García, X. (2015). La pronunciación del español: Fonética y enseñanza de lenguas. Alicante: Universidad de Alicante. Servicio de publicaciones.

Padilla García, X., Y Ruíz Gurillo, L. (2009). Dime cómo ironizas y te diré quién eres: Una aproximación pragmática a la ironía. Frankfurt: Peter Lang.

Instituto Cervantes (2006). Plan curricular del Instituto Cervantes. Niveles de referencia para el español. Madrid: Instituto Cervantes- Biblioteca nueva.

Ruíz GuRILLO, L. (2008). «El lugar de la ironía en la clase de ELE: más allá del Marco y del Plan Curricular», redELE: Revista Electrónica de Didáctica ELE, 14, 6. 


\section{Anexos}

4.1. Anexo 1 - Indicadores de la ironía

\section{UNDLCADORES DE LA RRONIA}

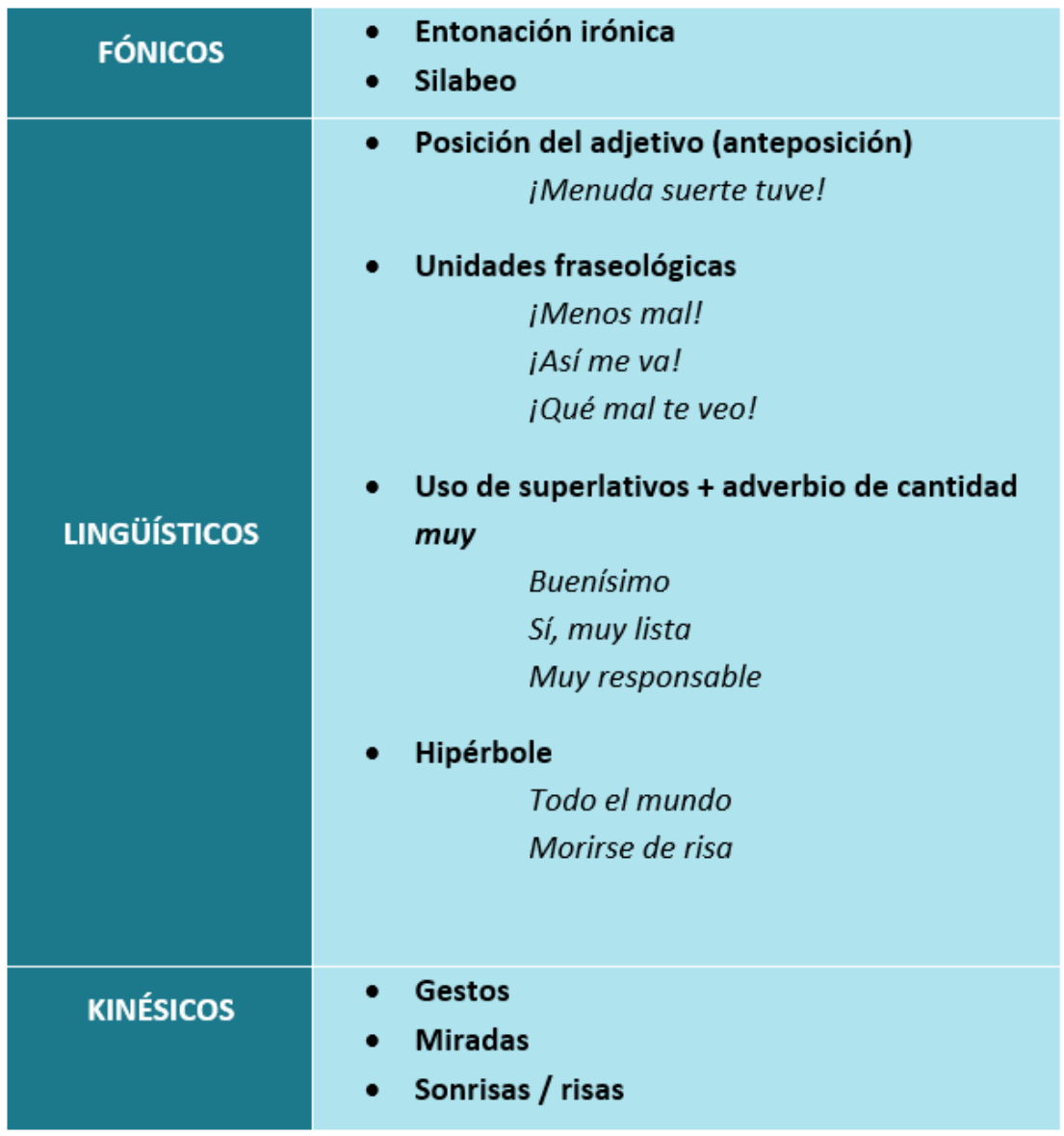


4.2. Anexo 2 - Ficha del alumno

\section{LA ENTONACIÓN DE LA IRONÍA}

1. Reflexiona sobre la ironía. Comenta con tu profesor/a y con tus compañeros/as lo que sabes acerca de la ironía.
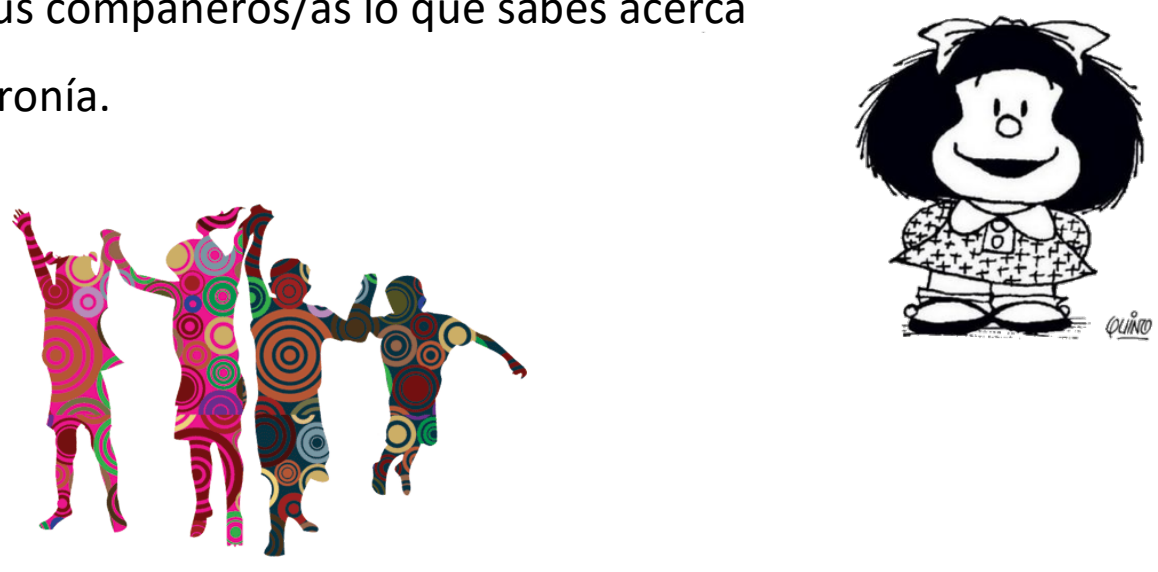

2. iEscucha y repite!

2.1. Presta atención a las diferentes entonaciones y irepite!

IRÓNICO

- Unidad fraseológica menos mal!

- Adverbio de cantidad muy muy lista

NO IRÓNICO 


\subsection{Balé con las ondas. Observa la gráfica y repite.}

DRO̊NICAS

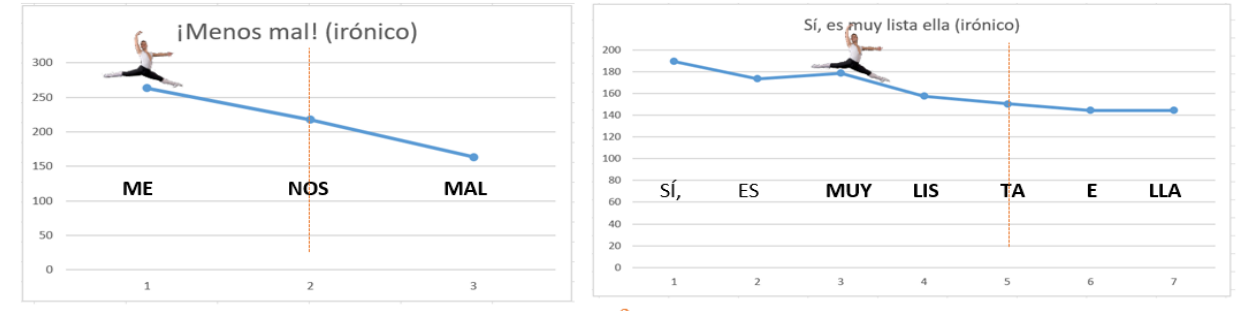

NO DRO̊NJCAS
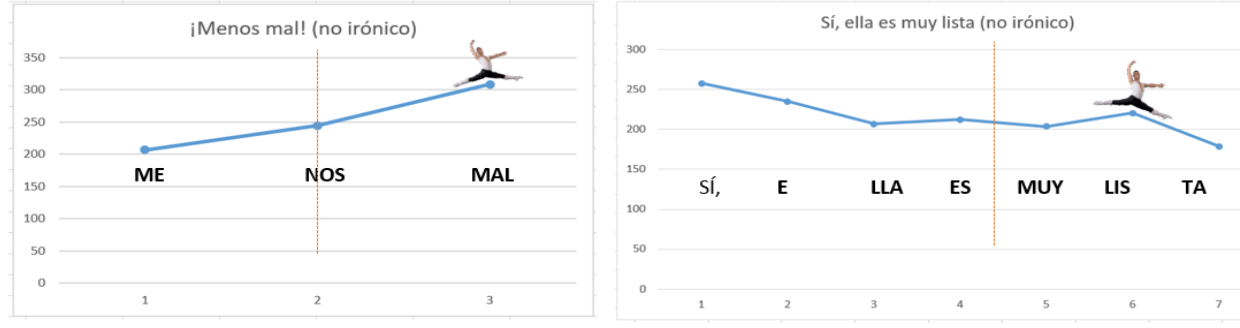

\subsection{Ahora, escucha estos ejemplos y escoge la entonación}

adecuada dependiendo del contexto, luego repítela.
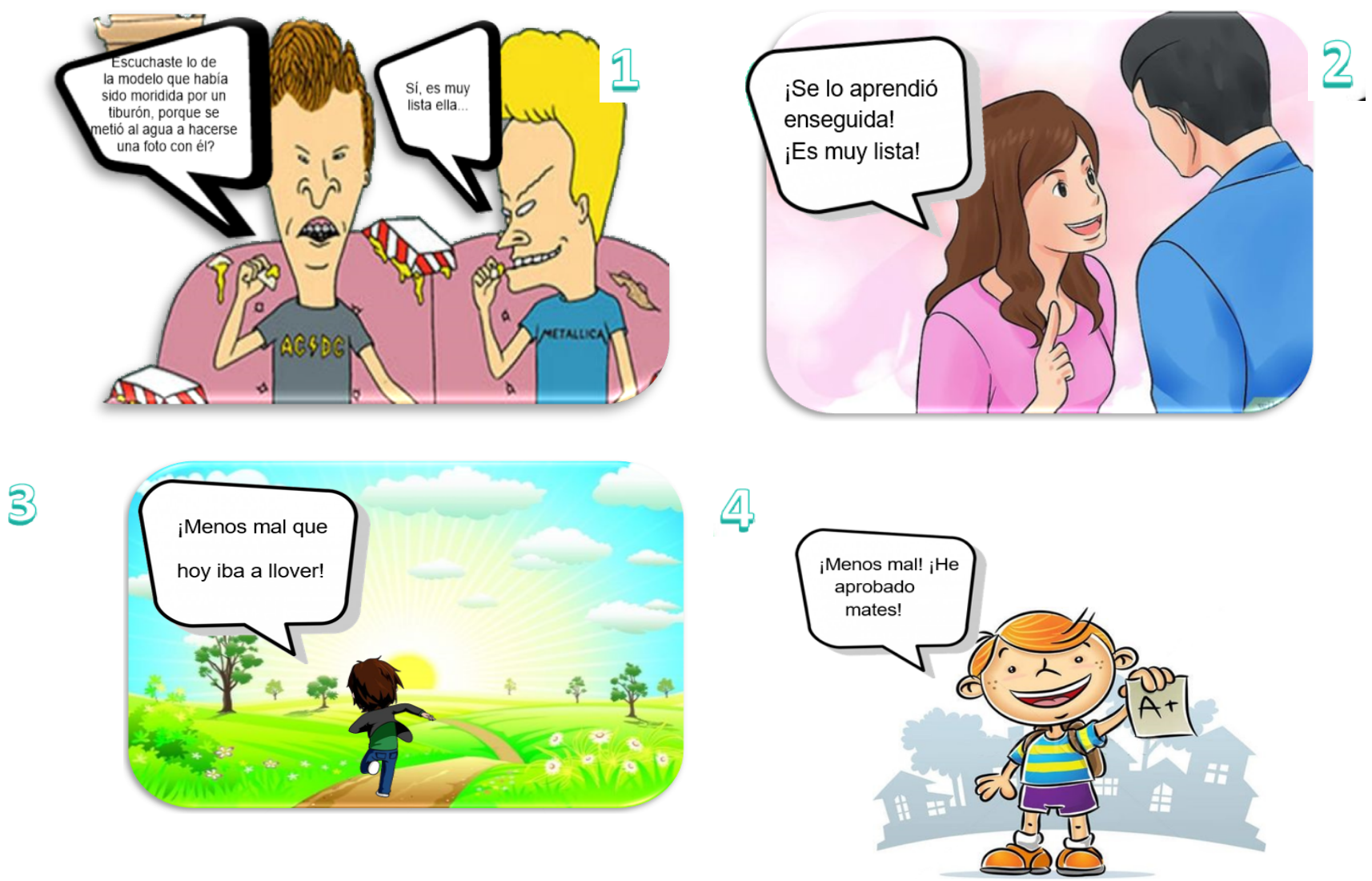


\section{Encuentra la ironía.}

3.1. Identifica la ironía en los siguientes fragmentos y di qué te ha ayudado a hacerlo.

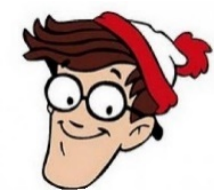

\section{AUDIO 1}

[dos amigas viendo un álbum de fotos]

A: Se hizo un moño chulísimo para la boda

B: Sí, sí, ipero era tan alto que ni entraba

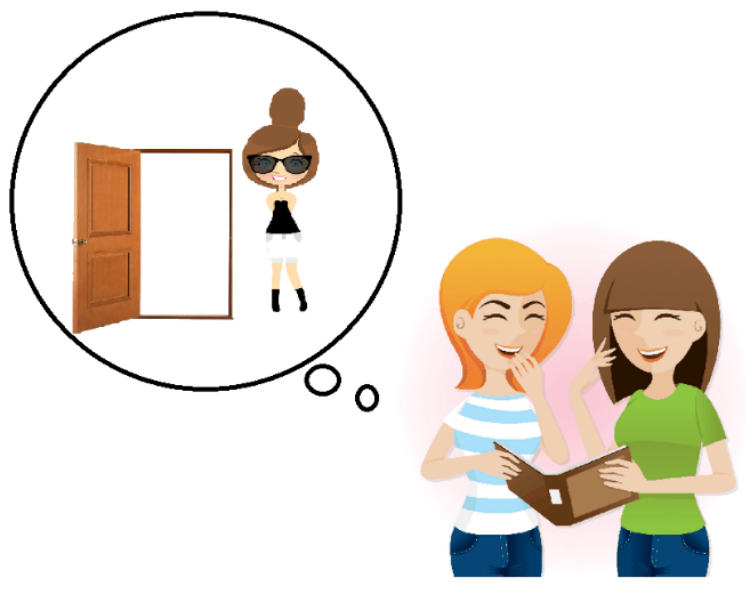

AUDIO 2

[unos padres hablando de su hijo]

A: Tranquila, seguro que

hace los deberes

B: Sí que los va a hacer, sí...

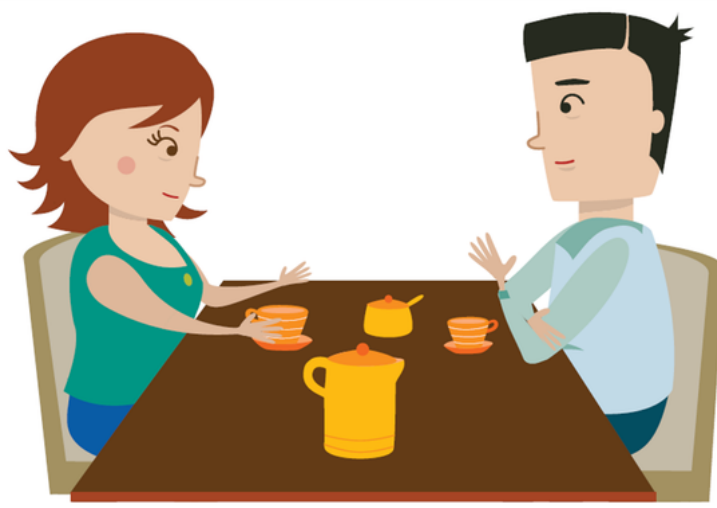




\section{AUDIO 3}

[de camino a casa, pasa un camión

y moja todos los apuntes de A]

A: Me encanta que todo me salga bien

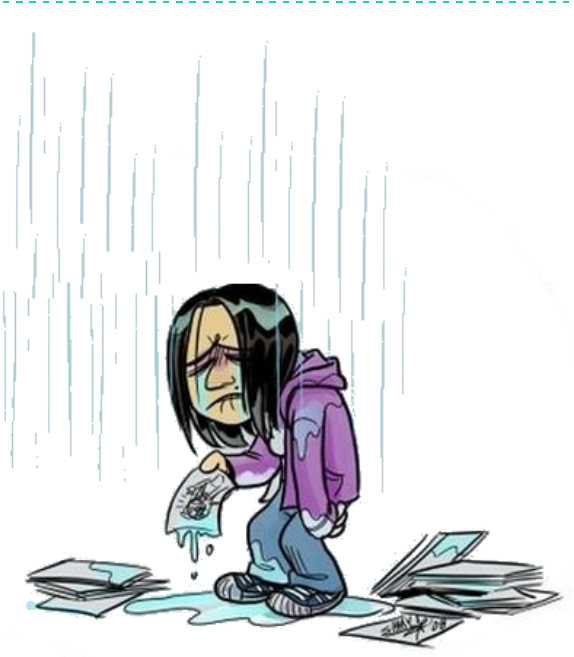

\section{Ironiza como puedas.}

4.1. Por grupos (3-4 pers.), coged un papel de cada caja: de la primera sacaréis una frase; de la segunda, su entonación irónica o no irónica. Deberéis ser capaces de pronunciar vuestra frase adecuadamente.

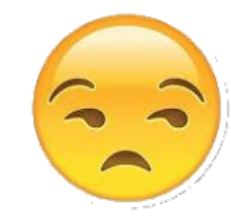

IRÓNICO NOIRÓNICO

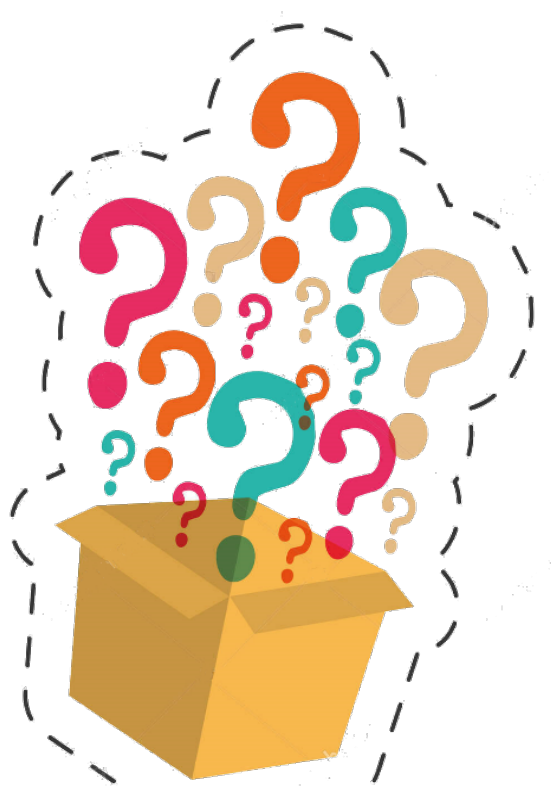


4.2. En casa, a partir de la frase y entonación que habéis sacado, deberéis crear un contexto adecuado. Se representará en forma de diálogo en la siguiente sesión.

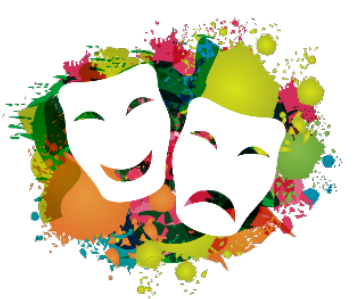

4.3. Además, en la próxima sesión, habréis de crear la gráfica correspondiente de vuestra frase, teniendo en cuenta la entonación, y la posición de la sílaba tónica. 


\subsection{Anexo 3 - Espectrogramas}

IRÓNICO

NO IRÓNICO

¡Menos mal!
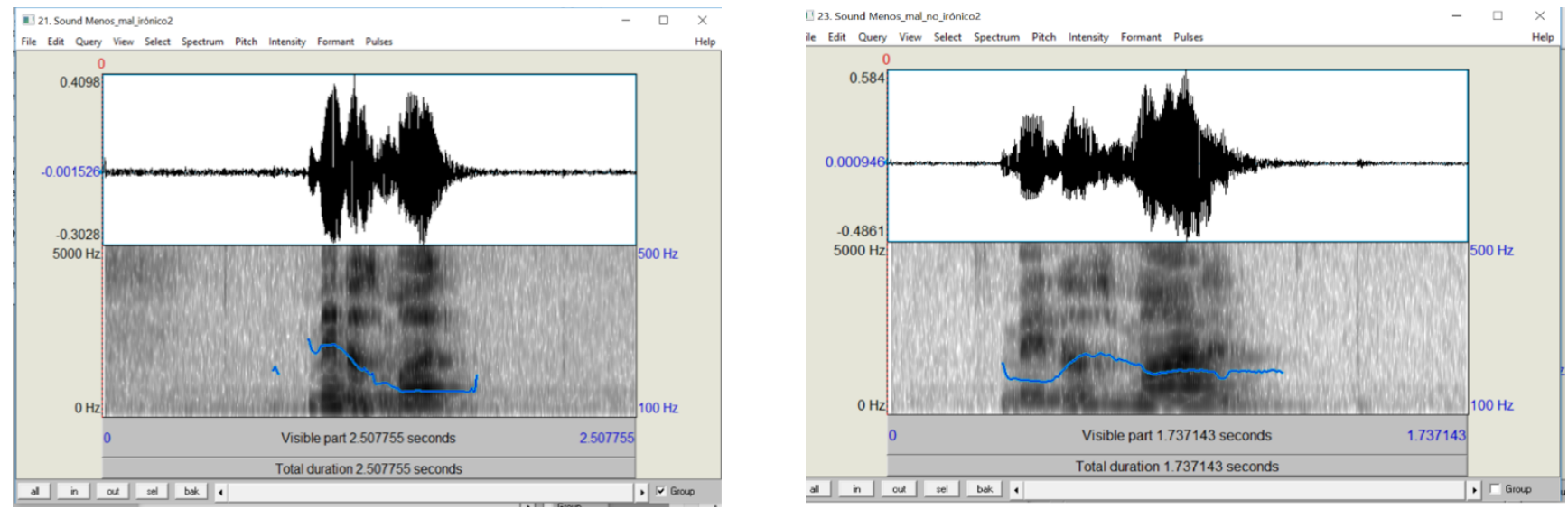

¡Muy lista!
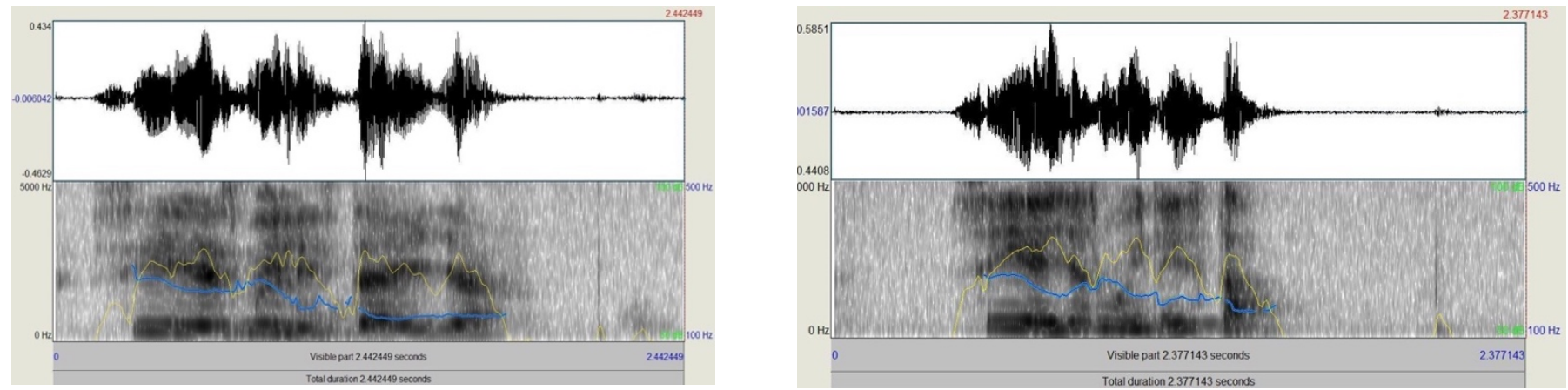

4.4. Anexo 4-Modelo tarea 4.3.

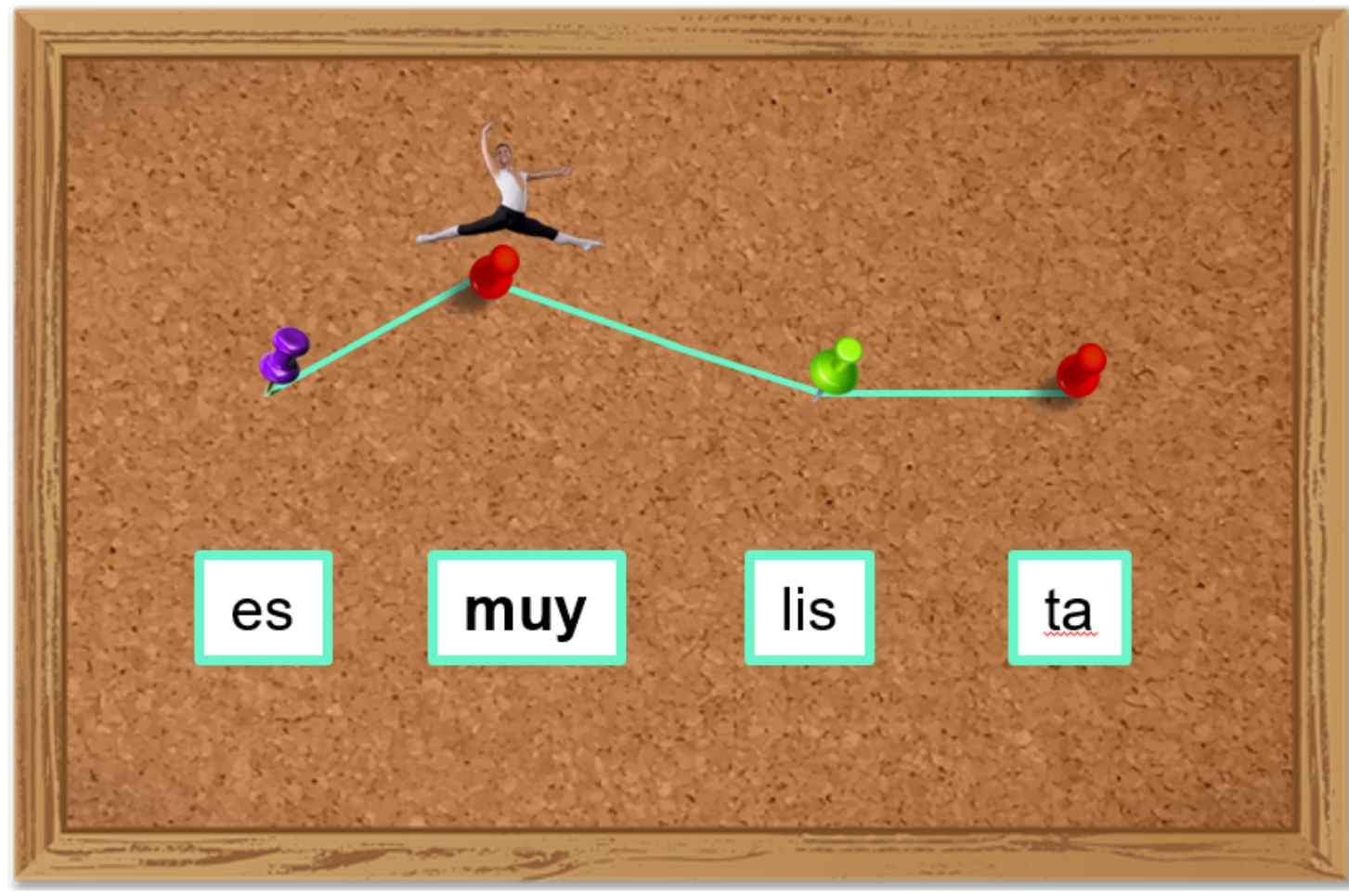


4.5. Anexo 5 - Propuesta fono-cognitiva

\begin{tabular}{|c|c|c|c|c|c|c|c|}
\hline $\begin{array}{c}\text { ELEMENTOS } \\
\text { DESTACABLES }\end{array}$ & & $\begin{array}{l}\text { Fase } 1 \\
\text { PERCEPCIÓN } \\
\text { MECÁNICA }\end{array}$ & $\begin{array}{c}\text { Fase } 2 \\
\text { PRODUCCIÓN } \\
\text { MECÁNICA }\end{array}$ & $\begin{array}{c}\text { Fase } 3 \\
\text { REFLEXIÓN }\end{array}$ & $\begin{array}{c}\text { Fase } 4 \\
\text { PERCEPCIÓN } \\
\text { CONSCIENTE }\end{array}$ & $\begin{array}{c}\text { Fase } 5 \\
\text { PRODUCCIÓN } \\
\text { CONSCIENTE }\end{array}$ & $\begin{array}{c}\text { Fase } 6 \\
\text { PRODUCCIÓN } \\
\text { INCONSCIENTE }\end{array}$ \\
\hline $\begin{array}{l}\text { Activación de } \\
\text { conocimientos previos } \\
\text { sobre la ironía }\end{array}$ & Introducción & & & & & & \\
\hline $\begin{array}{l}\text { ironía en L1 de los } \\
\text { alumnos } \\
\text { interculturalidad }\end{array}$ & Actividad 1 & & & & & & \\
\hline $\begin{array}{l}\text { Escucha de la entonación } \\
\text { irónica en los ejemplos } \\
\text { menos mal y muy listo/a }\end{array}$ & & $\begin{array}{c}\text { Actividad } 2 . \\
1\end{array}$ & & & & & \\
\hline $\begin{array}{l}\text { Repetición de la } \\
\text { entonación irónica de los } \\
\text { ejemplos }\end{array}$ & & & Actividad 2.2 & & & & \\
\hline $\begin{array}{l}\text { Representación gráfica de } \\
\text { las curvas melódicas de } \\
\text { los ejemplos, así como un } \\
\text { símil } \\
\text { para su rápida } \\
\text { memorización }\end{array}$ & & & & & $\begin{array}{l}\text { Actividad } 2.2 \\
\text { silabeo } \\
\text { Balé con } \\
\text { las ondas }\end{array}$ & & \\
\hline $\begin{array}{l}\text { Identificar las } \\
\text { particularidades de la } \\
\text { ironía } \\
\text { en ejemplos } \\
\text { contextualizados }\end{array}$ & & & & $\begin{array}{l}\text { Actividad } 3 \\
\text { iEncuentra } \\
\quad \text { la } \\
\text { ironia! }\end{array}$ & & & \\
\hline $\begin{array}{l}\text { Reproducción de las } \\
\text { entonaciones irónicas, } \\
\text { tanto } \\
\text { de los ejemplos vistos } \\
\text { como } \\
\text { de nuevos - con el mismo } \\
\text { patrón fónico }\end{array}$ & & & & & & $\begin{array}{l}\text { Actividad } \\
\quad 4.1 \\
\text { (juego) } \\
\text { iIroniza } \\
\text { como } \\
\text { puedas! }\end{array}$ & \\
\hline $\begin{array}{l}\text { Creación de contextos } \\
\text { válidos para los ejemplos } \\
\text { estudiados y su } \\
\text { representación en clase }\end{array}$ & & & & & & & $\begin{array}{l}\text { Actividad } 4.2 \text { y } \\
4.3 \\
\text { iIroniza como } \\
\text { puedas! }\end{array}$ \\
\hline
\end{tabular}

